Jurnal Keperawatan Silampari

Volume 5, Nomor 1, Desember 2021

e-ISSN: 2581-1975

p-ISSN: 2597-7482

DOI: https://doi.org/10.31539/jks.v5i1.3007

\title{
ANALISIS PELAKSANAAN PROGRAM PENCEGAHAN STUNTING
}

\author{
Yuli Zulaikha ${ }^{1}$, Yuanita Windusari ${ }^{2}$, Herawati Idris ${ }^{3}$ \\ Universitas Sriwijaya ${ }^{1,2,3}$ \\ haera@fkm.unsri.ac.id ${ }^{3}$
}

\begin{abstract}
ABSTRAK
Penelitian ini bertujuan untuk menganalisis secara mendalam mengenai pelaksanaan program pencegahan stunting di Puskesmas Air Beliti Kabupaten Musi Rawas. Desain penelitian yang digunakan penelitian kombinasi antara metode kuantitatif dengan metode kualitatif (mixed methods). Hasil penelitian menunjukkan bahwa responden paling dominan adalah berjenis kelamin perempuan yaitu $66,67 \%$. Sebagian besar berumur $21-30$ tahun yaitu $46,67 \%$, berpendidikan paling banyak adalah D3/Diploma yaitu 66,67\%, dan masa kerja lebih dari 7 tahun sebesar $40 \%$. Faktor yang berhubungan dengan keberhasilan program stunting di Pukesmas Air Beliti Kabupaten Musi Rawas adalah variabel karakteristik struktur instansi, jaringan dan komunikasi, dan kebutuhan masyarakat. Sedangkan faktor yang tidak berhubungan dengan keberhasilan program stunting yaitu budaya organisasi dan jaringan eksternal. Program pencegahan stunting yang dilakukan pihak Puskemas Air Beliti antara lain; 1) meningkatkan mutu gizi perseorangan, keluarga, dan masyarakat; 2) melakukan aksi bersama atau trobosan untuk pencegahan stunting, 3) melakukan strategi edukasi kesehatan dan gizi melalui kemandirian keluarga; dan melakukan gerakan 1000 HPK. Simpulan, pelaksanaan program pencegahan stunting di Puskesmas Air Beliti Kabupaten Musi Rawas secara umum sudah berjalan dengan baik dengan respon msyarakat yang positif. Faktor yang dapat mempenagruhi keberhasilan pelaksanaan program Stunting yaitu karakteristik struktur instansi, jaringan dan komunikasi, dan kebutuhan masyarakat.
\end{abstract}

Kata Kunci: Pelaksanaan, Pencegahan, Program, Stunting

\section{ABSTRACT}

This study aims to analyze the implementation of the stunting prevention program at the Air Beliti Health Center, Musi Rawas Regency. The research design used was a combination of quantitative and qualitative methods (mixed methods). The results showed that the most dominant respondent was female, namely 66.67\%. Most of them are 21-30 years old, which is $46.67 \%$, the most educated are D3/Diploma, which is $66.67 \%$, and $40 \%$ of the work period is more than seven years. Factors related to the success of the stunting program at the Air Beliti Public Health Center, Musi Rawas Regency, are the characteristics of the institutional structure, network and communication variables, and community needs. At the same time, the factors that are not related to the success of the stunting program are organizational culture and external networks. The stunting prevention programs carried out by the Air Beliti Health Center include; 1) improving the nutritional quality of individuals, families, and communities; 2) taking joint actions or breakthroughs for stunting prevention, 3) carrying out health and nutrition education strategies through family independence; and make 1000 HPK moves. In conclusion, implementing the stunting 
prevention program at the Air Beliti Health Center, Musi Rawas Regency, in general, has gone well with positive community responses. Factors that can influence the success of the stunting program implementation are the characteristics of the agency structure, network and communication, and community needs.

\section{Keywords: Implementation, Prevention, Program, Stunting}

\section{PENDAHULUAN}

Era digital saat ini menutut semua negara memacu pembangunan baik sumber daya alam maupun sumber daya manusianya. Pembangunan nasional yang berhubungan dengan peningkatan sumber daya manusia telah dicanangan dalam Undang-Uandang Dasar 1945. Untuk membangun sumber daya manusia secara berkelanjutan yang didasarkan atas visi pembangunan nasional, diperlukan pembanguan kesehatan demi mencapai Indonesia sehat. Hal ini sesuai undang-undang 1945 alinia 4 yang berbunyi melindungi segenap bangsa Indonesia dan seluruh tumpah darah Indoensia juga untuk memajukan kesejahteran umum dan mencerdaskan kehidupan bangsa. Untuk mencapai tujuan yang tercantum dalam udang-undang 1945 alinie 4 tersebut, maka pemerintah berupaya meyelenggarakan program pembangunan yang berkelanjutan, berencana dan terarah. Salah satu pembanguan yang terencana untuk menyiapkan generasi yang kuat di masa depan adalah pembangunan kesehatan, hal ini karena bangsa yang kuat adalah bansa yang sehat, pembangunan kesehatan akan terintergral dengan pembangunan nasional secara menyeluruh (Muthia \& Yantri, 2019).

Masalah kesehatan saat ini yang menganggu perkembangan generasi yang akan datang, salah satunya adalah kekurangan gizi. Akibat kekurangan gizi pada anak akan berdampak besar pada generasi yang akan datang. Salah satu masalah kesehatan yang serius harus ditangani di Indonesia adalah kasus stuting. Stuting menurut Supariasa \& Purwaningsih (2019) kondisi perkembangan anak balita yang gagal karena adanya kekurangan gizi kronis, adanya faktor rendahnya stimulus psikososial, serta paparan infeksi berulang terutama pada periode 1.000 Hari Pertama Kehidupan (1.000 HPK). Hal ini sering terjadi pada negara berkembang termasuk Indonesia. Stunting yang selama ini masih belum sepenuhnya dipahami oleh masyarakat luas. Masih banyaknya masyarakat yang beragapan bahwa stunting adalah hal biasa, dan masih adanya anggapan bahwa stunting adalah genetik (Yuliastini et al., 2020).

Stunting adalah ganguan pertumbuhan anak secara linier akibat adannya kekurangan asupan zat gizi secara kronis. Stunting juga dapat katakan sebagai penakit infeksi kronis yang ditunjukkan dengan nilai z-skor tinggi badan untuk umur $(\mathrm{TB} / \mathrm{U})<-2 \mathrm{SD}$. Berdasarkan data tersebut maka balita dikatakan stunting apabil memliki nilai z skor di bawah garis normal yaitu kurang dari -2SD, yang biasa dikatakan balita pendek. Sedangkan apabila kurang dari -3SD maka balitas dikategorikan sangat pendek (Kemenkes, 2018). Menurut WHO pengertian tentang stunting yaitu anak yang mengalami cacat pertumbuhan dan perkembangannya. Anak mengalami kekurangan gizi buruk, infeksi berulang dan stimulasi psikologisosial yang tidak memadai (Kwami et al., 2019).

Stunting memiliki konsekuensi ke depan pada anak yaitu kemampuan kognisi dan perkembangan fisik yang rendah sehingga berdampak pada pencegahan kapasitas anak saat dewasa nanti, stuting dapat berdampak pada produktiviats anak setelah dewasa. Anak yang stunting rentang terhadap berbagai penyakit degeneratif. Hasil penelitian mempredikasi dampak terjadinya stunting pada anak yaitu kerugian psikososial dan kesehatan mental pada anak-anak akan berakibat hilangnya PDB sampai 300 triliun rupiah setiap tahunnya. Hal ini 
menjadi masalah serius terhadap masa depan bangsa dan negara, karena anak-anak sekarang adalah masa depan bangsa dan negara (Yuliastini et al., 2020). Faktor stunting sangat kompleks, faktor utama adalah kurang pangan atau gizi tetapi faktor lainnya seperti pemberian makanan tidak tepat, layanan kesehatan yang buruk, dan sanitasi yang buruk juga penting (Dimitrova \& Muttarak, 2020).

Tahun 2013, di Indoensia data menunjukkan bahwa dari 4 bayi lahir, terdapat 1 bayi stunting. Hal ini berarti stunting terjadi sebelum anak lahir. Data juga menunjukkan setelah lahir yaitu anak berusia 12-23 bulan prevalensi stunting meningkat hampir $40 \%$. Pola stunting pada awal masa kanak-kana kini membuat periode sejak pembuahan hingga ulang tahun kedua seorang anak yaitu 1.000 hari pertama kehidupan menjadi periode window of opportunity atau kesempatan emas yang sangat penting untuk mencegah stunting pada anak. Masa tersebut adalah tumbuh kembang anak yang perlu diperhatikan (Purba, 2020)

Jika dibandingkan dengan negara lain yang memliki ekonomi setara di wilayah Asia Tenggara, Indonesia masih tertinggal. Prevelensi stunting di Indonesia pada tahun 2018 sebesar 29,9\%. Hal ini tidak sesuai dengan target pemerintah tahun 2015-2019 prevelensi stunting di Indoensia bisa menjadi 28\%. Data prevelsi stunting untuk anak balitas sebesar 30,8\% pada tahun 2018. Berdasarkan data-data di atas, maka masih perlu dikejar programprogram kementaraian kesehatan maupun lembaga terkait dalam rangka pencegahan prevelensi stunting. Kementerian kesehatan menargetkan tahun 2024 prevensi stanting di Indonesia menjadi 14\% (Kemenkes, 2018).

Prevalensi anak balita stunting di Provinsi Sumatera Selatan sebesar 31,7\% pada tahun 2018. Pada tahun 2019 angka tersebut mengalami pencegahan menjadi 29,0\% dengan rata-rata perubahan per tahunnya kurang lebih 1,3 persen. Namun, prevalensi stunting pada tahun 2019 masih tinggi jika dibandingkan dengan standar WHO yaitu prevalensi stunting dibawah 20 persen (Djide, 2021).

Berdasarkan data Dinas Kesehatan Sumatera Selatan per tahun 2018, balita stunting di 10 kabupaten/ kota di Sumatera Selatan dengan kasus terbanyak sebagai berikut pada Kabupaten Lahat sebanyak 48,10\%, Kabupaten Ogan Ilir 43,90\%, Kabupaten Pali 39,50\%, Kabupaten Empat Lawang 36,00\%, Kabupaten Musi Rawas 34,60\%, Kabupaten Muara Enim 34,40\%, Kabupaten Musi Rawas Utara 33,20\%, Kabupaten Ogan Komering Ulu 33,20\%, Kota Lubuk Linggau 32,00\% dan Pagar Alam 31,10\% (Apriani, 2020). Menurut hasil Riset Kesehatan Dasar (Riskesdas) pada tahun 2018 persentase stunting melebihi persentase nasional yakni sekitar 31 persen. Sedangkan pada tahun 2019 persentase stunting 28,98 persen. Berdasarkan laporan dari Aplikasi Pencatatan dan Pelaporan Gizi Berbasis Masyarakat (e-PPGBM) selama periode Januari dan Februari 2020, tercatat sebanyak 10.169 balita mengalami stunting.

Kabupaten Musi Rawas menduduki peringkat ke-5 pada balita yang mengalami stunting dari 17 kabupaten/ kota di Sumatera Selatan. Pada tahun 2018 tercatat pada data hasil surveilans gizi oleh Dinas Kesehatan Kabupaten Musi Rawas, sebanyak 1.499 anak di Kabupaten Musi Rawas mengalami stunting. Sedangkan pada tahun 2019, berdasarkan laporan dari Aplikasi Pencatatan dan Pelaporan Gizi Berbasis Masyarakat (e-PPGBM) tercatat 1.140 anak di Kabupaten Musi Rawas mengalami stunting. Namun berdasarkan data e-PPGBM per 24 November 2020, tercatat 1.930 anak di Kabupaten Musi Rawas mengalami stunting. Hal ini menunjukan penambahana yang signifikan.

Kasus stunting pada Kabupaten Musi Rawas berdasarkan hasil pengamatan terjadi pada semua puskesmas. Dari 19 puskesmas yang ada di Kabupaten Musi Rawas kasus stunting tertinggi ditemukan di wilayah kerja Puskesmas Megang Sakti, kasus cukup tinggi di Puskesmas Air Beliti dan kasus stunting rendah di Puskesmas L. Sidoharjo. Melihat 
sumber daya alam yang dimiliki tidak seharusnya Kabupaten Musi Rawas memiliki kasus stunting yang tinggi. Untuk mengetahui faktor yang menjadi penyebab masalah tersebut, maka perlu kajian untuk menganalisis bagaimana pelaksanaan program pencegahan stunting pada Kabupaten Musi Rawas dengan dilakukan study kasus pada puskesmas yang memiliki kasus stunting cukup tinggi dengan 115 kasus balita pendek dan sangat pendek yaitu Puskesmas Air Beliti Kecamatan Tuah Negri Kabupaten Musi Rawas.

\section{METODE PENELITIAN}

Desain Penelitiaan

Desain penelitian yang digunakan penelitian kombinasi antara metode kuantitatif dengan metode kualitatif (mixed methods). Desain campuran yang digunakan adalah sequential explanatory design. Desain ini peneliti mengutamakan terlebih dahulu analisa data kuantitatif, baru dilanjutkan dengan analisis data kualitatif.

Populasi penelitian ini adalah seluruh karyawan Puskesmas Air Beliti Kecamatan Tuah Negri Kabupaten Musi Rawas. Sedangkan sampel penelitian ini adalah sebagian karyawan Puskesmas Air Beliti Kecamatan Tuah Negri Kabupaten Musi Rawas yaitu karyaan yang menjadi tim program pecegahan stunting. Informan dalam penelitian ini adalah Kepala Dinas Kesehatan Kabupaten Musi Rawas, Kepala Puskesmas Air Beliti, Kasie Gizi dan Pemegang Program Gizi, Pemegang Program KIA Ibu dan Anak, Kepala Dusun, Pemegang Program Promkes dan ibu dengan balita stunting.

\section{Jenis, Sumber Data dan Instrumen Penelitian}

Jenis data penelitian ini adalah data primer, yaitu data yang langsung diperoleh dari responden atau informan. Sumber data diperoleh dari beberapa informan yang berkompeten dengan masalah yang dibahas. Metode pengumpulan data menggunakan kuesioner, wawancara mendalam, informasi yang digali adalah program pencegahan terjadinya stunting di wilayah kerja Puskesmas Air Beliti Kecamatan Tuah Negri Kabupaten Musi Rawas.

Adapun instrumen penelitian adalah kuesioner dan pedoman wawancara mendalam dengan mengumpukan informasi program stunting yang dilakukan Puskesmas Air Beliti yaitu meningkatkan mutu gizi perseorangan, keluarga, dan masyarakat; melakukan aksi bersama atau trobosan untuk pencegahan stunting, melakukan strategi edukasi kesehatan dan gizi melalui kemandirian keluarga; dan melakukan gerakan 1000 HPK.

\section{Analisis Data}

Analisis data kuantitatif peneitian ini terdiri dari analisis univariat dan bivariat. Alat analisis yang digunakan adalah chi square. Teknik analisis kualitatif, dengan mewawancara mendalam dari lapangan dipaparkan melalui paparan tertulis. Analisis data dilakukan dengan mengumpulkan data wawancara secara mendalam kepada pihak informan yang berkepentingan dengan masalah stunting yaitu kepala dinas kesehatan Kabupaten Musi Rawas. Kepala Puskesmas, Kepala Desa dan kader-kader Posyandu. Setelah data terkumpulkan maka penelti melkukan berbagai langkah antara lain data direduction, lalau data display, dan conclusion drawing/verification. 
HASIL PENELITIAN

Tabel. 1

Distribusi Frekuensi Responden

Menurut Karakteristik Responden

\begin{tabular}{|c|c|c|c|}
\hline No & Karakteristik & Jumlah (N) & Persetase $(\%)$ \\
\hline 1. & $\begin{array}{l}\text { Jenis Kelamin } \\
\text { 1. Laki-Laki } \\
\text { 2. Perempuan }\end{array}$ & $\begin{array}{c}5 \\
10\end{array}$ & $\begin{array}{l}33,33 \\
66,67\end{array}$ \\
\hline 2. & $\begin{array}{l}\text { Umur } \\
\text { 1. }>20 \text { Tahun } \\
\text { 2. } 21-30 \text { Tahun } \\
\text { 3. } 31-40 \text { Tahun } \\
\text { 4. } 41-50 \text { Tahun } \\
\text { 5. 51 -60 Tahun } \\
\text { 6. }>60 \text { Tahun }\end{array}$ & $\begin{array}{l}0 \\
7 \\
2 \\
3 \\
2 \\
1\end{array}$ & $\begin{array}{c}0.00 \\
46,67 \\
13,33 \\
20,00 \\
13,33 \\
6,67\end{array}$ \\
\hline 3. & $\begin{array}{l}\text { Pendidikan } \\
\text { 1. SLTA } \\
\text { 2. D3/Diploma } \\
\text { 3. S1/Sarjana } \\
\text { 4. S2/Magister }\end{array}$ & $\begin{array}{c}1 \\
10 \\
4 \\
0\end{array}$ & $\begin{array}{c}6,67 \\
66.67 \\
26.67 \\
0,00\end{array}$ \\
\hline 4. & $\begin{array}{l}\text { Masa Kerja } \\
1 .<2 \text { tahun } \\
\text { 2. } 2-4 \text { tahun } \\
\text { 3. } 5-7 \text { Tahun } \\
\text { 4. }>7 \text { Tahun }\end{array}$ & $\begin{array}{l}2 \\
4 \\
3 \\
6\end{array}$ & $\begin{array}{l}13,33 \\
26,67 \\
20,00 \\
40,00\end{array}$ \\
\hline
\end{tabular}

Berdasarkan tabel 1 responden paling dominan adalah berjenis kelamin perempuan yaitu $66,67 \%$. Sebagian besar berumur 21 - 30 tahun yaitu 46,67\%, berpendidikan paling banyak adalah D3/Diploma yaitu 66,67\%, dan masa kerja lebih dari 7 tahun sebesar $40 \%$.

Tabel. 2

Distribusi Frekuensi Responden

Menurut Variabel Independen dan Dependen

\begin{tabular}{llcc}
\hline No & \multicolumn{1}{c}{ Karakteristik } & Jumlah $(\mathrm{N})$ & Persetase (\%) \\
\hline 1. & Karakteristik struktur instansi & & \\
& 1. Baik & 8 & 53,3 \\
& 2. Kurang Baik & 7 & 46,7 \\
\hline 2. & Jaringan dan Komunikasi & \\
& 1. Baik & 10 & 66,7 \\
& 2. Kurang Baik & 5 & 33,3 \\
\hline 3. & Budaya Organisasi & & \\
& 1. Baik & 11 & 73,3 \\
& 2. Kurang Baik & 4 & 26,7 \\
\hline 4. & Kebutuhan Masyarakat & & \\
& 1. Baik & 8 & 53,3 \\
& 2. Kurang Baik & 7 & 46,7 \\
\hline 5. & Jaringan eksternal instansi & & 53,3 \\
& 1. Baik & 8 & 46,7 \\
\hline 6. & Kinerja/Keberhasilan Program & 7 & 60 \\
& Stunting & & 40 \\
\hline
\end{tabular}


Berdasarkan tabel 2 menujukkan bahwa proporsi karakteristik struktur instansi dari 15 responden menjawab baik lebih besar jika dibandingkan yang menjawab kurang baik yaitu 53,3\%. Proporsi jaringan dan komunikasi responden menjawab baik lebih besar jika dibandingkan yang menjawab kurang baik yaitu 66,7\%. Proporsi budaya organisasi responden menjawab baik lebih besar jika dibandingkan yang menjawab kurang baik yaitu 73,3\%. Proporsi kebutuhan masyarakat responden menjawab baik lebih besar jika dibandingkan yang menjawab kurang baik yaitu 53,3\%. Proporsi jaringan eksternal instansi responden menjawab baik lebih besar jika dibandingkan yang menjawab kurang baik yaitu 53,3\%. Proporsi kinerja/keberhasilan program stunting responden menjawab tinggi lebih besar jika dibandingkan yang menjawab tinggi yaitu $60 \%$.

\section{Hubungan Karakteristik Struktur Instansi dengan Kinerja/Keberhasilan Program Stunting}

Tabel. 3

Hubungan Karakteristik Struktur Instansi dengan Kinerja/Keberhasilan Program Stunting

\begin{tabular}{|c|c|c|c|c|c|c|c|c|}
\hline \multirow{4}{*}{$\begin{array}{c}\text { Karakteristik } \\
\text { Struktur Instansi }\end{array}$} & \multicolumn{4}{|c|}{ Kinerja/Keberhasilan } & \multirow{3}{*}{\multicolumn{2}{|c|}{ Total }} & \multirow{4}{*}{$\begin{array}{c}\text { OR } \\
95 \% \mathrm{CL}\end{array}$} & \multirow{4}{*}{$\begin{array}{c}\mathrm{P} \\
\text { Value }\end{array}$} \\
\hline & & rogra & & & & & & \\
\hline & \multicolumn{2}{|c|}{ Rendah } & \multicolumn{2}{|c|}{ Tinggi } & & & & \\
\hline & $\mathrm{N}$ & $\%$ & $\mathrm{~N}$ & $\%$ & $\mathrm{~N}$ & $\%$ & & \\
\hline Kurang Baik & 5 & 71.4 & 2 & 28,6 & 7 & 100 & 17,5 & \\
\hline Baik & 1 & 12,5 & 7 & 87,5 & 8 & 100 & $(1,223-$ & 0,020 \\
\hline Jumlah & 6 & 40 & 9 & 60 & 15 & 100 & $250,357)$ & \\
\hline
\end{tabular}

Berdasarkan tabel 3 diketahui bahwa pada kelompok responden yang menyatakan karakteristik struktur instansi kurang baik, proporsi kinerja/keberhasilan program stunting rendah terdapat lebih banyak yaitu $71,4 \%$. Hasil statistik diperoleh nilai-p $=0,020$, sehingga ada hubungan signifikan antara karakteristik struktur instansi dengan kinerja/keberhasilan program stunting di wilayah Puskesmas Air Biliti Kabupaten Musi Rawas.

\section{Hubungan Jaringan dan Komunikasi dengan Kinerja/Keberhasilan Program Stunting}

Tabel. 4

Hubungan Jaringan dan Komunikasi dengan Kinerja/Keberhasilan Program Stunting

\begin{tabular}{|c|c|c|c|c|c|c|c|c|}
\hline \multirow{4}{*}{$\begin{array}{l}\text { Jaringan dan } \\
\text { Komunikasi }\end{array}$} & \multicolumn{4}{|c|}{ Kinerja/Keberhasilan } & \multirow{2}{*}{\multicolumn{2}{|c|}{ Total }} & \multirow{4}{*}{$\begin{array}{c}\text { OR } \\
95 \% \mathrm{CL}\end{array}$} & \multirow{4}{*}{$\begin{array}{c}\mathrm{P} \\
\text { Value }\end{array}$} \\
\hline & & Progr & Stur & & & & & \\
\hline & \multicolumn{2}{|c|}{ Rendah } & \multicolumn{2}{|c|}{ Tinggi } & \multirow[b]{2}{*}{$\mathrm{N}$} & \multirow[b]{2}{*}{$\%$} & & \\
\hline & $\mathrm{N}$ & $\%$ & $\mathrm{~N}$ & $\%$ & & & & \\
\hline Kurang Baik & 4 & 80,0 & 1 & 20,0 & 5 & 100 & \multirow{3}{*}{$\begin{array}{l}16,0 \\
(1,093- \\
234,248)\end{array}$} & \multirow{3}{*}{0,025} \\
\hline Baik & 2 & 20,0 & 8 & 80,0 & 10 & 100 & & \\
\hline Jumlah & 6 & 40 & 9 & 60 & 15 & 100 & & \\
\hline
\end{tabular}

Berdasarkan tabel 4 diketahui bahwa pada kelompok responden yang menyatakan jaringan dan komunikasi kurang baik, proporsi kinerja/keberhasilan program stunting rendah diketahui memiliki persentase lebih besar yaitu 80\%. Hasil analisis chi square diketahui nilai-p $=0,025$, sehingga dapat disimpulkan terdapat hubungan yang signifikan jaringan dan komunikasi dengan kinerja/keberhasilan program stunting di wilayah Puskesmas Air Biliti Kabupaten Musi Rawas. 


\section{Hubungan Budaya Organisasi dengan Kinerja/Keberhasilan Program Stunting}

Tabel. 5

Hubungan Budaya Organisasi dengan Kinerja/Keberhasilan Program Stunting

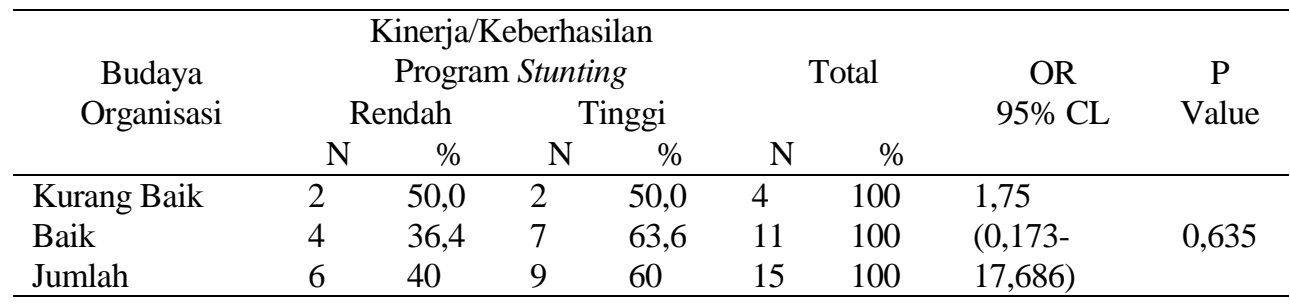

Berdasarkan tabel 5 diketahui pada kelompok responden yang menyatakan budaya organisasi kurang baik, proporsi kinerja/keberhasilan program stunting rendah diketahui memiliki persentase lebih besar yaitu 50. Hasil analisis diketahui nilai $p=0,635$, sehingga tidak terdapat hubungan antara budaya organisasi dengan kinerja/keberhasilan program stunting di wilayah Puskesmas Air Biliti Kabupaten Musi Rawas.

\section{Hubungan Kebutuhan Masyarakat dengan Kinerja/Keberhasilan Program Stunting}

Tabel. 6

Hubungan Kebutuhan Masyarakat dengan Kinerja/Keberhasilan Program Stunting

\begin{tabular}{|c|c|c|c|c|c|c|c|c|}
\hline \multirow{4}{*}{$\begin{array}{c}\text { Kebutuhan } \\
\text { Masyarakat }\end{array}$} & \multicolumn{4}{|c|}{ Kinerja/Keberhasilan } & \multirow{2}{*}{\multicolumn{2}{|c|}{ Total }} & \multirow{4}{*}{$\begin{array}{c}\text { OR } \\
95 \% \mathrm{CL}\end{array}$} & \multirow{4}{*}{$\begin{array}{c}\mathrm{P} \\
\text { Value }\end{array}$} \\
\hline & & Progra & Stun & & & & & \\
\hline & \multicolumn{2}{|c|}{ Rendah } & \multicolumn{2}{|c|}{ Tinggi } & & & \\
\hline & $\mathrm{N}$ & $\%$ & $\mathrm{~N}$ & $\%$ & $\mathrm{~N}$ & $\%$ & & \\
\hline Kurang Baik & 5 & 71.4 & 2 & 28,6 & 7 & 100 & 17.5 & \\
\hline Baik & 1 & 12,5 & 7 & 87,5 & 8 & 100 & $(1,223-$ & 0,020 \\
\hline Jumlah & 6 & 40 & 9 & 60 & 15 & 100 & $250,357)$ & \\
\hline
\end{tabular}

Berdasarkan tabel 6 diketahui pada kelompok responden yang menyatakan kebutuhan masyarakat kurang baik, proporsi kinerja/keberhasilan program stunting rendah diketahui memiliki persentase lebih besar yaitu $71,4 \%$. Hasil analisis diketahui nilai $p=0,020$, sehingga terdapat hubungan signifikan kebutuhan masyarakat dengan kinerja/keberhasilan program stunting di wilayah Puskesmas Air Biliti Kabupaten Musi Rawas.

\section{Hubungan Jaringan Eksternal Instansi dengan Kinerja/Keberhasilan Program Stunting}

Tabel 7

Hubungan Jaringan Eksternal Instansi

Dengan Kinerja/Keberhasilan Program Stunting

\begin{tabular}{|c|c|c|c|c|c|c|c|c|}
\hline \multirow[t]{3}{*}{$\begin{array}{c}\text { Jaringan } \\
\text { Eksternal Instansi }\end{array}$} & \multicolumn{4}{|c|}{$\begin{array}{l}\text { Kinerja/Keberhasilan } \\
\text { Program Stunting }\end{array}$} & \multicolumn{2}{|c|}{ Total } & \multirow[t]{3}{*}{$\begin{array}{c}\mathrm{OR} \\
95 \% \mathrm{CL}\end{array}$} & \multirow[t]{3}{*}{$\begin{array}{c}\mathrm{P} \\
\text { Value }\end{array}$} \\
\hline & \multicolumn{2}{|c|}{ Rendah } & \multicolumn{2}{|c|}{ Tinggi } & & & & \\
\hline & $\mathrm{N}$ & $\%$ & $\mathrm{~N}$ & $\%$ & $\mathrm{~N}$ & $\%$ & & \\
\hline Kurang Baik & 4 & 57,1 & 3 & 42,9 & 7 & 100 & 4,00 & 0,205 \\
\hline Baik & 2 & 25,0 & 6 & 75,0 & 8 & 100 & $(0,447-$ & \\
\hline Jumlah & 6 & 40 & 9 & 60 & 15 & 100 & $35,788)$ & \\
\hline
\end{tabular}


Berdasarkan tabel 7 diketahui bahwa pada kelompok responden yang menyatakan jaringan eksternal instansi kurang baik, proporsi kinerja/keberhasilan program stunting rendah diketahui memiliki persentase lebih besar yaitu 57,1\%.Hasil analisis chi square diketahui nilai $\mathrm{p}=0,205$, sehingga dapat disimpulkan bahwa tidak terdapat hubungan antara jaringan esternal instansi dengan kinerja/keberhasilan program stunting di wilayah Puskesmas Air Biliti Kabupaten Musi Rawas.

Status gizi anak balita menjadi salah satu alat ukur atau indikator yang digunakan MDGs untuk menilai tingkat pencapaian kesehatan suatu negara. Balita atau anak di bawah 5 tahun rentang akan kekurangan gizi, sehingga menjadi rentang stunting. Masalah anak pendek (stunting) merupakan salah satu permasalahan gizi di Indonesia yang serius. Hal ini karena dampak dari masalah stunting akan berpengaruh pada perkembangan anak, yang pada akhirnya akan berpengarub pada generasi bangsa dan negara kedepan. Oleh karena itu perlu kebijakan dari pemerintah baik pusat maupun daerah dalam melaksanakan intervensi baik gizi spesifik dan gizi sensitif.

Upaya pemerintah dalam menurunkan angka stunting di Indonesia sudah banyak dilakukan, salah satunya dengan mengeluarakan kebijakan dan regulasi intervensi stunting. Kebijakan pemerintah dilaksanakan meteri kesehatan. Kebijakan menteri kesehatan, yang membuat program pecegahan stuntinng. Program pencegahan stunting yang dilakukan dengan mengitervensi gisi spesifik dan mengitervensi gizi sensitif.

Hasil data wawancara yang dilakukan pada kepada Kepala Dinas Kesehatan Kabupaten Musi Rawas menyatakan bahwa upaya pemerintah melalui Dinas Kesehatan melakukan pencegahan stunting dengan cara intervensi gizi spesifik. Intervesi gizi spesifik dilakukan dengan program pendampingan pada keluarga sadar gizi. Dinas Kesehatan melakukan sosialisasi dengan mengadakan pertemuan untuk menyampaikan informasi tentang gizi yang dampaknya pada stunting.Hal ini sesuai pernyataan kepada Dinas Kesehatan sebagai berikut:

“......Dinas melakukan pendampingan kelompok keluarga sadar gizi dan melakukan sosialisasi, setiap bulan dinas melakukan pertemuan untuk menyampaikan informasi soal gizi. Tim kami memberikan informsi tentang stunting, peyebabnya dan penagulangganya....”.

Hal ini juga di dukung pernyataan Kepala Desa Darmasakti yang menyatakan:

“....Desa melakukan sosialisasi melalui perangkat desa dan BPD yang kemudian di informasikan kemasyarakat untuk dilanjutkan ke kader Posyandu untuk mendata anakanak yang memiliki gejala stunting...”.

Berdasarkan hasil wawancara di atas, menunjukkan bahwa program pelaksanaan pencegaan stunting yang dikukan pemerintah Indonesia saat ini sudah dipahami oleh perangkat bawahanya baik dinas kesehatan kabupaten, maupun pemerintah dibawahnya lagi yaitu tingkat desa. Informasi tentang pencegahan stunting sudah disosialisasikan secara pertahap sesuai tahapan aturan yang ada. Hanya saja banyak kendala atau faktor masih tingginya kasus stunting di tingkat puskesmas, yang dipengaruhi tingkat pendidikan masyarakat desa yang masih rendah, struktur masyarakat, tingkat pendidikan, keterbatasan tenagakesehatan dan dan status ekonomi.

Sesuai hasil wawancara dengan salah satu orangtua yang memiliki anak stunting menyatakan:

“...Ya saya berpendidikan SMP, kurang tahun akan gejala stunting, hanya seperti orang biasa anak saya beri asupan ASI, sedangkan makan tambahan kalau sudah umur 2 
bulan, biasa nasi tim kalau ada sayuran, seadanya bu, lihat ekonomi keluarga juga untuk memberikan tambahan makanan..."

Hasil wawancara dengan kader posyandu, menyatakan:

“....kendala atau faktor penyebaba adanya stunting, sebagian kami sebagai petugas pedataan kadang kesulitan karena wilayah Puskesmas Air Beliti yang struktur tidak megelompok, kadang ada yang tidak bisa dijangkau. Selain itu tenaga kesehatan dari puskesma kadang masih terbatas....".

Hasil wancara di atas menunjukkan bahwa faktor yang mempengaruhi anak stunting, antara lain tingkat pendidkkan orang tua khusnya ibu yang masih rendah. Rata-rata di wilayah Puskesmas Air Beliti orang tua yang memliki anak stunting berpendidikan SMP, sehingga tingkat pengetahun tentang stunting masing kurang. Tingkat ekonomi keluarga. Ekonomi keluarga berperan penting dalam mencukupi gizi keluarga khusunya anak-anak. Struktur masyarakat, tempat tinggal msyarakat yang tidak mengelompok, atau berjarak sehingga seulit dijangkan juga menajdi salah satu kendala petugas dalam menangani stunting, selan itu keterbatasan tenaga kesehatan juga menjadi faktor kendala tersenidri, karena di pedesaan tenaga kerja kesehatan terbatas, sehingga penangananya menjadi lambat.

Sedangkan upaya yang dilakukan pemerintah lewat pemerintah kecamatan atau wilayah puskesmas, melalui program pencegahan stunting. Program pencegahan stunting yang dilakukan pihak puskemas antara lain:

\section{Meningkatkan Mutu Gizi Perseorangan, Keluarga, dan Masyarakat}

Hasil wawancara dengan Kepala Puskesmas Air Beliti menyatakan bahwa program pencegahan stunting yang dilakukan puskesman yaitu memberikan informasi ke masyarakat melalui kader-kader baik PKK maupun posyandu terkait jenis makanan ibu hamil atau setelah melahirkan yang harus dikonsumsi dan mensosialisasikan makana bergizi kepada masyarakat secara luas. Kade-kader yang diberi penyuluhan agar dapat menyampaikan ke msyarakat secara luar tentang bagaimana memenuhi gisi yang seimbang. Hal ini sesuai pernyataan Wakil Program Gizi Puskesmas Air Beliti berikut:

“...tim gizi yang saya tugaskan memberikan informasi gizi ke masyarakat, kita harus memberikan pemahaman kepada masyarakat tentang makanan yang sehat dan bergisi itu apa saja, kami juga mensosialisakan ke kader-kader agar bisa menyampiakan ke masyarakat, bagamiana untuk memenuhi gizi yang seimbang tidak makan itu-itu saja...."

\section{Melakukan Aksi Bersama atau Trobosan untuk Pencegahan Stunting}

Hasil wawancara mendalam yang dilakukan dengan Kepala Puskesmas Air Beliti menyatakan bahwa dalam rangka aksi bersama untuk melakukan trobusan pencegahan stunting dilakukan kerjasama antara puskesmas dengan pihak desa melalui kader-kader yang ditunjuk. Kader-kader yang ada secara bersama-sama dengan pihak puskesmas melakukan penyuluhan kepada masyarakat untuk dapat melaksanakan program gerakan msyarakat sehat. Program ini dilakukan secara bersama-sama antara pihak puskesmas dan kader seperti melakukan senam bersama, setelah itu diadakan penyuluhan.

Hal ini dapat dilihat pada pernyataan kepala Puskesmas Air Beliti berikut:

“...ya tim kami melakukan aksi bermsa dengan pihak desa-desa wilayah Puskesmas sini. Pihak kami bersama kepala desa meberikan pemahaman kepada kader untuk lebih memperhatikan msyarakat ekitar wilayah desa bahwa stunting itu bukan akibat 
keturunan tetapi karena adanya masalah kesehatan yang perlu secara serius ditangani, hal ini karena msyarakat masih kurang memahami pentingnya gizi anak supaya tidak stunting. Kami melakukan gerakan bersama baik dengan kepala desa, kader untuk memasang paflet dengan bekerjsama secara lintas sektor....".

\section{Melakukan Strategi Edukasi Kesehatan danGizi melalui Kemandirian Keluarga}

Hasil wawancara mendalam kepada Kepala Puskesmas Air Beliti, menyatakan bahwa upaya mencegahan stunting dapat dilakukan melalui strategi edukasi kesehatan dan gizi melalui kemandirian keluarga, yaitu mengadakan penyuluhan-penyuluhan tentang gizi di desa-desa melalui kader-kader posyandu. Hasil penyuluhan diharapkan dapat meningkatkan pengetahuan msyarakat tentang gizi seimbang sehingga dapat mencegah stunting. Hal ini dapat dilihat pada pernyataan Kepala Puskesmas Air Beliti berikut:

“....Puskesmas memiliki program khusus dengan melakukan penyuluhan-penyuluhan, jadwal yang sudah terlaksana dengan baik pada posyandu, jadi kader-kader dan msyarakat yang datang di posyandu kami berikan penyuluhan tentang gizi, disitulah kita beri edukasi kesehatan untuk masyarakat secara bertahap....".

\section{Melakukan Gerakan Masyarakat Hidup Sehat (GERMAS)}

Pihak Puskesmas Air Beliti sudah melakukan pencegahan stunting secara lintas sektor. Pihak puskesmas terus mensosilasasikan gerakan masyarakat hidup sehat, dengan melakukan stimulus berolah raga 30 menit pada pagi hari sebelum beraktifitas kerja. Kesadaran masyarakat akan kesehatan menjadi pondasi negara menjadi sehat dan kuat sehingga ekonomi menjadi kuat. Gerakan masyarakat sehat terus di sosialisasikan sampai ke pelosok desa melalu penyuluhan kader-kader PKK dan posyandu. Hal ini dapat dilihat pada pernyataan kepala Puskesmas Air Beliti berikut:

“....Ya perlunya kerjasama antar sektoral semua pihak, supaa program stuating berjalan secara optimal, salah satunya pukesmas mengajak semua msyarakat untuk memiliki kesadaran hidup sehat dapat....”.

\section{Melakukan Gerakan 1000 HPK}

Hasil wawancara mendalam yang dilakukan peneliti dengan Kepala Puskesmas Air Beliti, menyatakan bahwa gerakan 1000 HPK dilakukan pihak puskesmas dengan berkerjasama dengan bidan-bidan desa. Bidan-bidan desa diberi tugas untuk memantau ibuibu hamil dari trimester pertama sampai bayi berusia 24 bulan, bidan desa meberikan pengertian agar ibu-ibu hamil usia tersebut memenuhi kebutuhan gizi baik untuk ibunya maupun bayinya, dengan diberikan PMT. Hal ini dapat dilihat pada pernyataan kepala Puskesmas Air Beliti berikut:

“....Gerakan 1000 HPK telah dilakukan oleh bidan-bidan desa untuk memantau kehamilan dari trimester pertama sampai bayi burusia 24 bulan agar kebutuhan gizi ibu hamil dan bayinya dapat dipenuhi dengan diberikan PMT..."

\section{PEMBAHASAN}

Upaya pemerintah melalui Dinas Kesehatan melakukan pencegahan stunting dengan cara intervensi gizi spesifik. Intervesi gizi spesifik dilakukan dengan program pendampingan pada keluarga sadar gizi. Dinas Kesehatan melakukan sosialisasi dengan mengadakan pertemuan untuk menyampaikan informasi tentang gizi yang dampaknya pada stunting. 
Jika pada anak pada pertubuhannya selema 2 bulan berturut-turt tidak naik, maka perlu konsultasi pada dokter, bahwa anak perlu ada gangguan pertumbuhan, hal ini dapat disebabkan mungkin karena asupan gizi yang anak butuhkan tidak sebanding dengan energi yang dikeluarkannya selama beraktivitas. Maka program konseling harus mengevaluasi menu MPASI yang anda berikan kepada anak, apakah cakupan gizinya sudah sesuai dengan kebutuhan anak, porsi makan sudah sesuai dengan kebutuhan tubuhnya, variasi menu yang diberikan sudah mengandung semua zat gizi dalam tubuh. Hal-hal itulah yang perlu diperhatian pada orangtua apabila anaknya mengalami gangguan pertumbuhan.

Hal ini sesuai temuan Supariasa \& Purwaningsih (2019) pencegahan stunting dapat dilakukan dengan program pemberdayaan masyarakat. Masyarakat diajak mendukung pemerintah yaitu intervensi gizi spesifik. Dinas kesehatan melalui puskesmas wilayah kerja masing-masing untuk bisa melibatkan masyarakat dalam kegiatan intervesi gizi spesifik. Seperti melibatkan PKK dan kader-kader posyandu untuk dapat menyampaikan informasi ke masyarakat luas tentag stunting.

Hasil penelitin Muthia \& Yantri (2019) menemukan bahwa salah satu faktor penting dalam pemberdayaan masyarakat adalah keluarga, dalam hal ini adalah ibu. Ibu berperan penting dalam mengatasi pencegahan stunting pada anaknya. Pengetahuan ibu tentang tambahan ASI ekslusif, waktu pemberian MP-ASI dan Jenis M-ASI sesuai tahapan umur sangat penting.

Kendala atau faktor masih tingginya kasus stunting di tingkat puskesmas, yang dipengaruhi tingkat pendidikan masyarakat desa yang masih rendah, struktur masyarakat, tingkat pendidikan, keterbatasan tenaga kesehatan dan dan status ekonomi. Hal ini dukung peneliti Supariasa \& Purwaningsih (2019) yang menemukan bahwa faktor dominan stunting adalah ekonomi keluarga. Selanjutnya faktor pemberian ASI, jumlah keluarga tingkat pendidikan ayah ibu, ketahanan pangan keluarga, ketepatan pemberian MP-ASI, tingkat kesehatan.

\section{Program Pencegahan Stunting yang Dilakukan Pihak Puskemas Air Beliti Meningkatkan Mutu Gizi Perseorangan, Keluarga, dan Masyarakat}

Pemerintah telah berupaya melalu instansi terkait dalam hal ini puskesmas telah melakukan peningkatan mutu gizi masyarakat dengan melakukan sosialisasi tentang pemahaman msyarakat tentang nilai gizi dan makanan yang bergizi kepada kader-kader desa, ibu PKK, dengan melakukan kegiatan PMTA. Pentingnya sosialisasi kepada perorangan, keluarga dan masyarakat luas tentang makan yang seimbang sesuai standar gizi yang diharapakan dapat mencegah terjadinya stunting pada anak.

Hasil ini didukung peneliti Muthia \& Yantri (2019) yang menemukan untuk mendukung program pemerintan dalam menurunkan angka stunting, maka perlu dukungan masyarakat secara lintas sektoral. Selain bidang kesehatan untuk mengatasi masalah stunting diperlukan bidang non kesehatan, seperti dinas pangan, kependudukan dan keluarga berencana. Bidang-bidang ini harus sinergi dalam penganan stunting di Indoensia. Program tersebut diturunakan ke lembaga puskesmas untuk menyelenggarakan program intervensi gizi spesifik dengan melibatkan beberapa lintas program seperti gizi, KIA ibu, KIA anak, Promkes, Kesling dan lintas sektoral seperti kecamatan, desa, kader kesehatan, dinas pendidikan, dinas sosial, PKK, BAZNAS dan KUA. 


\section{Melakukan Aksi Bersama atau Trobosan untuk Pencegahan Stunting}

Dalam rangkat mecari trobosan prorgam yang dapat mencegah terjadinya stunting, pihak puskesmas melakukan aksi bersama dengan kader desa. Kader yang lebih memliki informasi ke masyarakat diajak bersama mensosialisaskan sebagai aksi bersama pencegahan stunting. Masyarakat perlu diberi informasi atau dipahamkan bahwa stunting bukan keturunan tetapi gangguan kesehatan yang diakibatkan gizi buruk. Peragkat desa, kader dan pihak puskesmas bersama-sama memasang paflet yang isiinya ajakan untuk sadar gizi untuk mencegah stunting.

Hasil penelitian Vaivada et al., (2020) membuktikan bahwa aksi bersama dengan perangkat desa, kader posyandu dengan melibatkan tokoh-tokoh masyarakat dalam mensosialisakan program intervensi gizi spessiak, mampu menurunkan angka stunting di daerah wilayah puskesmas.

\section{Melakukan Strategi Edukasi Kesehatan dan Gizi melalui Kemandirian Keluarga}

Strategi edukasi kesehatan dan gizi yang dilakukan pihak Puskesmas Air Beliti melalui kemandarian kelaurga, pihak puskesmas memberikan penyuluhan-penyuluhan ke masyarakat tentang gizi seimbang dan pentingnya pencegahan stunting sejak dini, dengan memberikan informasi pada orang tua yaitu agar orangtua tahu akan pentingnya kecukupan gizi pada anak sehingga akan berbepenagruh pada tumbuh kembang anak. Sebuah penelitian tahun 2019 menyimpukan bahwa anak balita penting dalam memenui nutrisinya. Nutrisi penting yang perlu diberikan pada anak balita yaitu vitamin A, Zinc, mikronitrien, omega 3 dan protein.

Hal ini mendukung hasil penelitian Supariasa \& Purwaningsih (2019) bahwa sasaran penyuluhan pihak puskesmas dalam rangka edukasi kesehatan dan gizi adalah kader-kader posyandu. Penyuluhan yang dilakukan dapat meningkatkan pengetahuan ibu tentang kesehatan dan gizi, yang berdampak pada stunting.

\section{Melakukan Gerakan Masyarakat Hidup Sehat (GERMAS)}

Pihak Puskesmas Air Beliti sudah melakukan pencegahan stunting secara lintas sektor. Pihak Puskesmas terus mensosilasasikan gerakan masyarakat hidup sehat, dengan melakukan stimulus berolah raga 30 menit pada pagi hari sebelum beraktifitas kerja. Kesadaran masyarakat akan kesehatan menjadi pondasi negara menjadi sehat dan kuat sehingga ekonomi menjadi kuat. Gerakan masyarakat sehat terus di sosialisasikan sampai ke pelosok desa melalu penyuluhan kader-kader PKK dan posyandu.

\section{Melakukan Gerakan 1000 HPK}

Puskesmas Air Beliti gerakan 1000 HPK dilakukan pihak puskesmas dengan berkerjasama dengan bidan-bidan desa. Bidan-bidan desa diberi tugas untuk memantau ibuibu hamil dari trimester pertama sampai bayi berusia 24 bulan, bidan desa memberikan pengertian agar ibu-ibu hamil usia tersebut memenuhi kebutuhan gizi baik untuk ibunya maupun bayinya, dengan diberikan PMT. Program ini dilakukan dengan kerjasama antar pihak puskesmas dengan bidan-bidan yang menagani ibu hamil, hingga program bisa tepat sasasran.

\section{SIMPULAN}

Ada hubungan yang signifikan antara karakteristik struktur instansi dengan kinerja/keberhasilan program stunting. Ada hubungan yang signifikan antara jaringan dan komunikasi dengan kinerja/keberhasilan program stunting. Ada hubungan yang signifikan 
antara kebutuhan masyarakat dengan kinerja/keberhasilan program stunting. Tidak ada hubungan yang signifikan antara budaya organisasi dengan kinerja/keberhasilan program stunting. Tidak ada hubungan yang signifikan antara jaringan eksternal instansi dengan kinerja/keberhasilan program stunting.

Upaya pencegahan stunting yang dilakukan pemerintah lewat Puskesmas Air Beliti Kecamatan Tuah Negari Kabupaten Musi Rawas yaitu dengan cara intervensi gizi spesifik. Intervensi gizi spesifik dilakukan dengan metode pendampingan pada keluarga sadar gizi. Sosialisasi dengan mengadakan pertemuan untuk menyampaikan informasi tentang gizi yang dampaknya pada stunting.

Faktor-faktor yang mempengaruhi stunting di wilayah Puskesmas Air Biliti yaitu tingkat pendidikan masyarakat desa yang masih rendah, struktur masyarakat, tingkat pendidikan, keterbatasan tenaga kesehatan dan status ekonomi. Program pencegahan stunting yang dilakukan pihak Puskemas Air Beliti antara lain; 1) meningkatkan mutu gizi perseorangan, keluarga, dan masyarakat; 2) melakukan aksi bersama atau trobosan untuk pencegahan stunting, 3) melakukan strategi edukasi kesehatan dan gizi melalui kemandirian keluarga; dan melakukan gerakan 1000 HPK.

\section{SARAN}

Untuk pihak puskesmas supaya terus memperhatikan dan meningkat struktur instansi yaitu susunan tim pencegahan stunting supaya sesuai dengan program yang dicanangkan, perlu perubahan susuanan tim kerjanya untuk mengaomodasi pelaksanaan program. Perlunya peningatan jaringan dan komunikasi yaitu perlu diintensifkan lagi kegiatan rapatrapat dengan kader-kader untuk membahas program penegarahn stunting. Pihak Pukesmas Air Beliti supaya meningkatkan koordinasi dengan kader-kader dan bidan-bidan desa untuk mengetahui kebutuhan pelayanan masyarakat. Pelayanan yang diberikan supaya sesuai dengan harapan masyarakat.

\section{DAFTAR PUSTAKA}

Dimitrova, A., \& Muttarak, R. (2020). After the Floods : Differential Impacts of Rainfall Anomalies on Child Stunting in India. Global Environmental Change, 64(13), 102130. https://doi.org/10.1016/j.gloenvcha.2020.102130

Djide, N. A. N. (2021). Hubungan Intervensi Spesifik dari Indikator Program Indonesia Sehat dengan Pendekatan Keluarga (Pis-Pk) dengan Prevalensi Stunting di 10 Desa Lokus Program Pencegahan Stunting di Kab. Banggai Tahun 2018-2019. Jurnal Kesehatan Masyarakat, 12(5), 121-231. http://repository.unhas.ac.id/id/eprint/2880/

Kemenkes, R. (2018). Profil Kesehatan Indonesia Tahun 2017. Jakarta: Kementerian Kesehatan RI

Kwami, C. S., Godfrey, S., Gavilan, H., Lakhanpaul, M., \& Parikh, P. (2019). Water, Sanitation, and Hygiene: Linkages with Stunting in Rural Ethiopia. Int. J. Environ. Res. Public Health, 16, 3793, 2-21. https://pubmed.ncbi.nlm.nih.gov/31600942/

Muthia, G., \& Yantri, E. (2019). Evaluasi Pelaksanaan Program Pencegahan Stunting Ditinjau dari Intervensi Gizi Spesifik Gerakan 1000 HPK Di Puskesmas Pegang Baru Kabupaten Pasaman. Jurnal Kesehatan Andalas, 8(4), 100-108. DOI: 10.25077/jka.v8i4.1125

Purba, R. O. (2020). Analisis Implementasi Program Intervensi Gizi Spesifik dan Intervensi Gizi Sensitif dalam Penurunan Angka Kejadian Stunting pada Balita di Kabupaten Langkat Tahun 2018. Jurnal Kesehatan, Universitas Sumatra Utara, 8(4), 109-185. https://repositori.usu.ac.id/handle/123456789/29349 
Supariasa, I. D. N., \& Purwaningsih, H. (2019). Faktor-Faktor yang Mempengaruhi Kejadian Stunting pada Balita di Kabupaten Malang. Karta Raharja, 1(2), 55-64. http://ejurnal.malangkab.go.id/index.php/kr

Vaivada, T., Akseer, N., Akseer, S., Somaskandan, A., Stefopulos, M., \& Bhutta, Z. A. (2020). Stunting in childhood: an overview of global burden, trends, determinants, and drivers of decline. The American Journal of Clinical Nutrition, Volume 112, Issue Supplement.

Yuliastini, S. R. I., Sudiarti, T., Sartika, R. A. D. (2020). Current Research in Nutrition and Food Science Factors Related to Stunting among Children Age 6-59 Months In Babakan Madang Sub-District, West Java, Indonesia. Current Research in Nutrition and Food Science Journal, 8(2), 454-461. DOI:10.12944/CRNFSJ.8.2.10 